\title{
Os lagos do lavrado de Boa Vista - Roraima: fisiografia, físico-química das águas, mineralogia e química dos sedimentos
}

\author{
Maria Ecilene Nunes da Silva Meneses ${ }^{1}$, Marcondes Lima da Costa ${ }^{2}$ \& \\ José Augusto Vieira Costa ${ }^{3}$
}

\begin{abstract}
Resumo A paisagem da porção nordeste do estado de Roraima é formada por uma superfície aplanada, vegetada por savanas, onde se desenvolvem inúmeros lagos, brejos e veredas colonizadas por Mauritia flexuosa. Estes lagos possuem formas variadas, entretanto, predominam as goticulares, circulares, elipsoidais e geminadas, estando geralmente relacionados aos pequenos cursos d'água (igarapés) constituindo suas cabeceiras. Suas bacias lacustres são pequenas e rasas e o nível d'água é sazonalmente controlado, desse modo, no período de estiagem vários lagos, brejos e veredas secam e estressam gramíneas e elementos de Mauritia flexuosa. Esses lagos são colonizados por densas comunidades de macrófitas aquáticas principalmente por ciperáceas que podem ocupar toda a extensão do lago ou apresentar uma distribuição zonada, circular e concêntrica cercando uma zona central mais profunda, borbulhante, indicativo de olho d'água. Os lagos não apresentam sedimentos finos próprios, e o seu substrato é formado apenas por material arenoso, com grãos angulosos e subangulosos, de baixa esfericidade, constituídos essencialmente por quartzo com uma pequena participação de caulinita e goethita. A composição química é assim caracterizada pelos altos teores de $\mathrm{SiO} 2$ e baixos teores de $\mathrm{A} 12 \mathrm{O} 3$ e Fe2O3, correlacionáveis aos sedimentos da Formação Boa Vista. As feições lacustres externas e internas sugerem que a ocorrência destes lagos no ambiente plano das savanas está relacionada ao afloramento do lençol freático, que sazonalmente intercepta as depressões do terreno, ou aflora nas áreas planas da superfície, na forma de olhos d'água, dando origem aos lagos e brejos. No conjunto, a paisagem de lagos e veredas formada por campos abertos e verdes constitui-se um sistema impar no contexto dos cenários amazônicos, que devido à acelerada e desordenada expansão urbana da cidade de Boa Vista vem sofrendo sérios impactos ambientais que incluem a extinção precoce de muitos lagos e brejos e o comprometimento da qualidade das águas lacustres através de práticas antrópicas tais como, a lavagem de roupas e o lançamento indiscriminado de efluentes domésticos em suas bacias.
\end{abstract}

Palavras-chave: Fisiografia dos lagos, composição granulométrica, mineralógica e química dos sedimentos, origem dos lagos, Boa Vista - Roraima.

\begin{abstract}
The lakes from Boa Vista, Roraima state: physiography, water physical-chemistry, mineralogy and chemistry of sediments. The landscape of northeast portion of the Roraima state is formed by a plain surface, covered by savanna, where many lakes, wetlands and Mauritia flexuosa paths occur. These lakes exhibit several shapes, but the most frequent ones are drop-shape, circular, ellipsoid and twin shapes, being generally related to small water courses (igarapés) like its headwaters. The lacustrine basins are very small and shallow. The water's level is seasonally controlled, during the drought season several lakes, wetlands and paths dry and stress the grassy ones and the Mauritia flexuosa. The lakes vegetation is compost by dense communities of aquatic macrophytes, mainly for Cyperaceae, which occupies whole lake or distributes in a circular and concentric zone, with a deeper and bubbling center area, indicative of water spring. The lakes don't present own fine sediments, its substratum's material is mostly sandy and the grains show no roundness until to low roundness as well as low sphericity. They are essentially constituted of quartz, being less frequent kaolinite. The chemical composition displays high concentrations of $\mathrm{SiO} 2$ and low values of $\mathrm{Al} 2 \mathrm{O} 3$ and $\mathrm{Fe} 2 \mathrm{O} 3$ allowing to correlate them to Boa Vista Formation sediments. The external and internal lacustrine features suggest that occurrence of these lakes in savanna environment are related to near surface groundwater, that during the rainy season intercepts the shallow land surface depressions, in the form of springs forming the lakes and wetlands. The whole landscape of lakes formed by green and open fields represents a singular lake system in the Amazon region which due the accelerate and disordered urban expansion of the Boa Vista city suffers environmental impacts including the extinction of many lakes and alteration of the waters quality through of anthropogenic activities such as clothes laundering and end destination of domestic effluents.
\end{abstract}

Keywords: Lake's physiography, granulometrical, mineralogical and chemical composition of the sediments, origin of the lakes, Boa Vista - Roraima.

1 - Centro de Geociências da Universidade Federal do Pará, Belém, Pará, Brasil. E-mail: mariaecilene@yahoo.com.br

2 - Centro de Geociências da Universidade Federal do Pará, Belém, Pará, Brasil. E-mail: mlc@ufpa.br

3 - Instituto de Geociências da Universidade Federal de Roraima, Boa Vista, Roraima, Brasil. E-mail: vieira@dgl.ufrr.br 
INTRODUÇÃO Ao longo das extensas paisagens fluviais que caracterizam a região amazônica é encontrada uma infinidade de lagos que se apresentam em tamanhos e formas variadas. Muitos destes lagos são típicos de áreas inundáveis (várzeas) que mantêm com os cursos fluviais conexões temporárias ou permanentes (Moreira-Turcq et al. 2004) e têm como característica principal a grande variação no nível de suas águas (Junk, 1980). Muitos outros são de meandros abandonados muito comuns ao longo de rios como o Madeira, Purus, Juruá e seus afluentes (Costa et al. 2005). Há também os lagos de barragem (ria-lakes) de formas dendríticas, cuja formação é atribuída à acumulação de sedimentos fluviais na foz de antigos rios (Esteves, 1998).

Além dos lagos originados por processos fluviais, encontram-se também na região Amazônica, lagos completamente isolados da rede fluvial, como por exemplo, os lagos desenvolvidos em depressões sobre crostas lateriticas, que sustentam platôs, e são conhecidos principalmente nas regiões de Carajás (Costa et al. 2005, Sifeddine et al. 2001), Seis Lagos (Correa \& Costa, 1997; Bush et al. 2002 e 2004) e Maicuru (Costa 1991).

Outros exemplos de lagos atípicos ao sistema flúvio-lacustre mencionado para a região amazônica são os inúmeros lagos pequenos e rasos (objeto deste estudo) que ocupam a baixa planície nordeste do estado de Roraima, mais conhecida por lavrado. Estes lagos, cuja origem ainda permanece incógnita se, desenvolvem sobre uma extensa superfície de aplanamento, vegetada por savanas configurando um cenário muito distinto daqueles encontrados nos domínios amazônicos (Simões Filho et al. 1997). Em outras regiões da Amazônia, vários trabalhos envolvendo lagos têm sido realizados ao longo das últimas décadas. O estudo das águas e dos sedimentos de fundo de bacias lacustres permite conhecer suas características limnológicas (Sioli, 1984, Melack \& Fisher, 1990, Carvalho et al. 2001) e avaliar suas condições paleoambientais e flutuações climáticas (Cordeiro et al. 1997, Behling \& Costa, 2000 e 2001, Behling et al. 2001, Sifeddine et al. 2004, Costa et al. 2005, Irion et al. 2006). Da mesma forma avaliar o ciclo do carbono (Moreira-Turcq et al. 2004, Turcq et al. 2002), a dinâmica das inundações e o fluxo de nutrientes (Junk, 1980, Sippel et al. 1992, Mertes, 1994, Junk, 1997, Hess et al. 2003, Viers et al. 2005), etc. Em Roraima, onde bacias lacustres são uma forte característica do lavrado, seus lagos, por outro lado, ainda não foram adequadamente investigados. As informações disponíveis se restringem a simples descrição de suas formas (Barbosa \& Ramos, 1959 e Franco et al. 1975). Por outro lado Absy et al. (1997) e Simões Filho et al. (1997) concentram-se em estudos palinológicos e nas características dos sedimentos de lagos da região nordeste e sul do Estado. Latrubesse \& Nelson (2001) estudaram a região no entorno da cidade de Boa Vista, e concluem que os lagos estão associados a campos de dunas remanescentes fortemente erodidos, e formados por deflação. Estes lagos localizam-se de fato em áreas de campo de dunas. Desta forma se questiona qual seria a origem dos demais lagos da região, uma vez que, se distribuem por toda a savana de Roraima, ao contrário dos depósitos eólicos, que são restritos a regiões dos rios Cauamé, Tacutu e na foz do rio Mucajaí. O presente trabalho tem como objetivo a caracterização dos processos de formação dos lagos no entorno da cidade de Boa Vista, e avaliar possíveis impactos antrópicos urbanos sobre os mesmos, até porque muitos destes lagos encontram-se sob pressão da expansão da cidade. Ao mesmo tempo procura identificar possíveis relações entre os sedimentos dos lagos e aqueles da planície de inundação do rio Branco, no sentido de caracterizá-los como lagos de planície de inundação ou não. Para tanto, foram investigadas as características morfológicas dos lagos, realizadas análises granulométricas, mineralógicas e químicas dos sedimentos encontrados em seus substratos e no entorno e os parâmetros físico-químicos de suas águas.

\section{CARACTERÍSTICAS GERAIS DA ÁREA DE ES-}

TUDO A região lacustre em estudo está localizada no nordeste do estado de Roraima, a oeste e sudoeste da cidade de Boa Vista, capital do referido Estado (coordenadas geográficas: $60^{\circ} 37^{\prime}$ e $60^{\circ} 47^{\prime}$ Oeste de Greenwich e $2^{\circ} 45^{\prime}$ e $2^{\circ} 53^{\circ}$ Norte), na zona setentrional da Amazônia Brasileira (Fig. 1). Esta região lacustre se situa próxima à margem direita do rio Branco, um rio de águas brancas, na classificação limnológica de Sioli (1984).

A cidade de Boa Vista encontra-se sob tropical úmido (Awi na classificação de Köppen). O verão chuvoso se estende normalmente de abril a setembro e o período seco de outubro a março. O mês de janeiro em geral é o mês mais seco, com precipitação média inferior a $60 \mathrm{~mm}$. A precipitação média anual oscila em torno de $1.750 \mathrm{~mm}$ e a temperatura média anual é de $27,4^{\circ} \mathrm{C}$ (Lopes, inédito).

A paisagem da região lacustre estudada está representada por a uma superfície plana e baixa denominada por Franco et al. (1975) Pediplano do Rio Branco - Rio Negro. Nesse pediplano as altitudes variam entre 85 e 140 metros acima do nível do mar (Costa, 1999). A vegetação dominante é do tipo savanas (Veloso et al. 1975; Miranda \& Absy, 1997), com estrato herbáceo representado pelos gêneros Andropogon sp, Trachypogon sp, Aristida sp, Axonopus sp, e Mesosetum sp (Poaceae). Freqüentemente intercalam-se espécies arbustivas típicas do cerrado brasileiro como a Curatella americana (Dilleniaceae) e a Byrsonima crassifolia (Malpighiaceae). A Mauritia flexuosa (Arecaceae), conhecida popularmente como buriti, é também muito comum nesta paisagem. Ela ocupa as áreas brejosas que formam as veredas similares aquelas do Brasil Central, além de ocupar parcialmente as margens de vários igarapés. Estes brejos e igarapés assim como também os lagos estudados, fazem parte ou se situam dentro da bacia do rio Branco, o principal curso fluvial da região e o maior tributário do rio Negro.

A geologia da área está representada pelos sedi- 


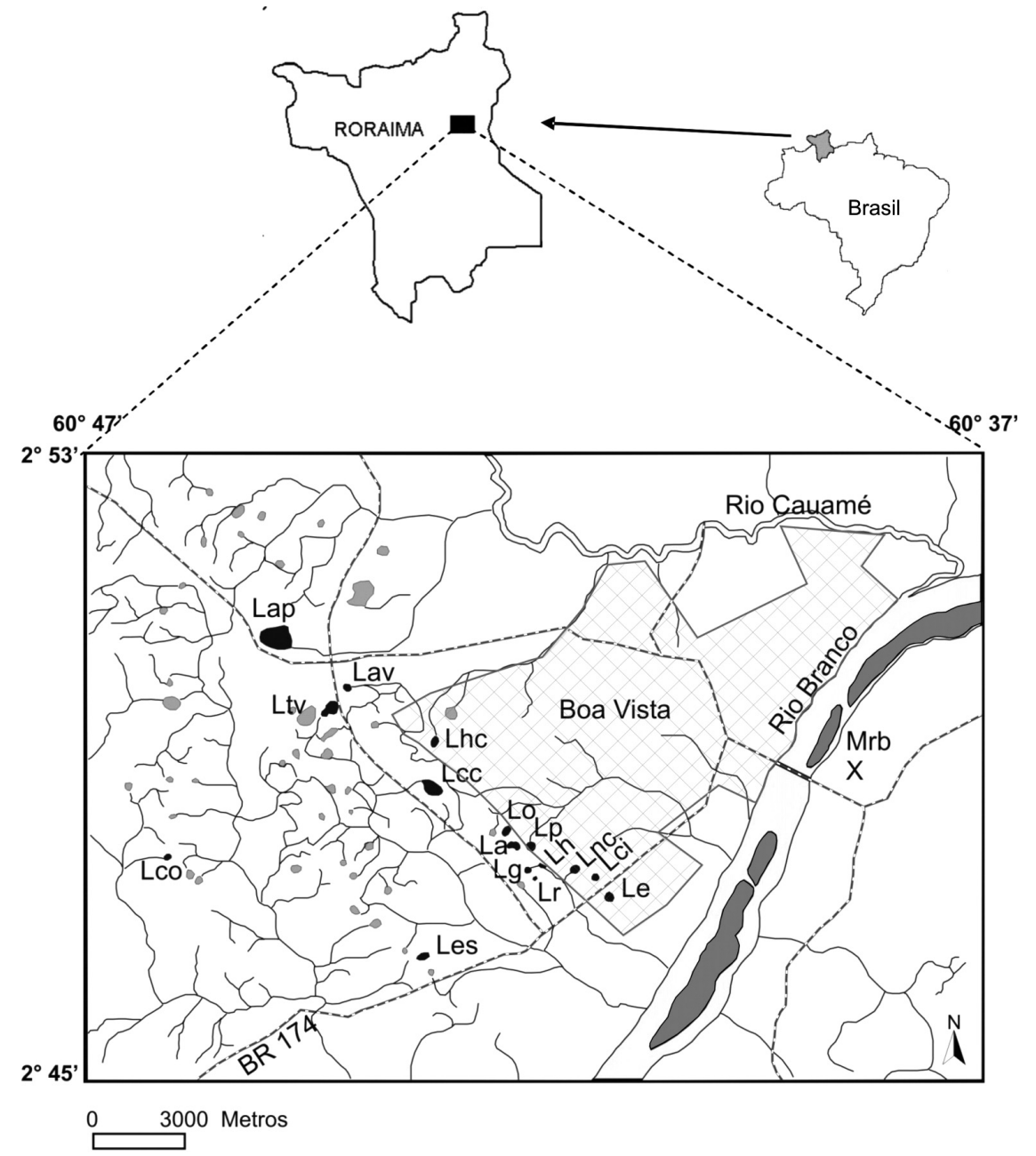

Figura 1 - Localização geográfica da área mostrando a cidade de Boa Vista e os lagos em seu entorno, destacando-se ainda os lagos que foram selecionados para amostragem.

\section{LEGENDA}

Lagos amostrados

Lagos não amostrados

$\bigcirc$ Barras de canal

$\sim$ Drenagem

- Principais vias de acesso

Área urbana

$X$ Mrb - margem rio Branco

Lap - Lago Apoteri

Lav - Lago do Velho

Ltv - Lago do Trevo

Lhc - Laqo Hélio Campos

Lcc - Lago Conjunto Cidadão

Lo - Lago do Operário

La - Lago do Apressado

Lp - Lago Piscicultura

Lg - Lago das Garças

Lh - Lago das Hortas

Lr - Lago Redondo

Lnc - Lago Nova Cidade

Lci - Lago Cidade

Les - Lago da Estrada

Le - Lago da EMBRAPA

Lco - Lago dos Costas mentos cenozóicos da Formação Boa Vista (Barbosa \& Ramos, 1959; Melo et al. 1978). De acordo com Montalvão et al. (1975) ela é constituída por sedimentos predominantemente arenosos, mal selecionados, com argilas arenosas e níveis de cascalhos intercalados. O pacote de sedimentos apresenta cerca de 15 metros de espessura máxima na área de estudo (Reis et al. 2001).

MATERIAIS E MÉTODOS Caracterização dos lagos As formas, tamanhos, sazonalidade, presença de vegetação e relação com a drenagem fluvial foram analisados a partir da interpretação de imagens de satélite Landsat ETM+ georreferenciadas (cobertura em outubro de 2002 e março de 2004), com auxílio do Sistema de Informação Geográfica - SIG e do software ArcView-3.2, além de imagens obtidas através de sobrevôo com aeronave monomotor.

Trabalhos de campo Foram realizados durante o mês de outubro de 2004, apoiados por imagens de satélite. Em 14 lagos foram realizadas medidas de profundidades com apoio de eco-batímetro portátil, determinados os parâmetros físico-químicos e realizadas coletas de sedimentos nos substratos e no entorno de suas bacias. Os parâmetros físico-químicos das águas (temperatura, $\mathrm{pH}$, condutividade elétrica, sólidos totais dissolvidos - STD e oxigênio dissolvido) foram determinados in loco com o auxílio de potenciômetro portátil marca Hanna modelo HI991300 da Universidade Federal do Pará. Também foram feitas observações quanto à pressão urbana em alguns lagos situados em áreas urbanas, bem como o comportamento da população local em relação aos mesmos.

As amostras de sedimentos no entorno e como substrato foram coletadas nos intervalos de 0-20 e de 20-40 cm de profundidade, com o auxílio de um trado manual. No sentido de efetuar comparações entre os sedimentos lacustres e os sedimentos da planície do rio Branco, coletaram-se também amostras na sua margem esquerda, junto às cavas de argila para cerâmica vermelha (Fig. 1). As amostras de sedimentos foram secas a temperatura ambiente, desagregadas e quarteadas. Alíquotas foram separadas para as análises granulométricas, mineralógicas e químicas.

Análises laboratoriais As análises granulométricas consistiram na separação das frações areia, areia fina, silte e argila. Ela foi feita através de peneiramento 
a seco, utilizando-se um conjunto de peneiras da série Tyler: $2.00,1.41,1.00,0.710,0.500,0.350,0.250$, $0.171,0.088,0.062,0,042 \mathrm{~mm}$ de abertura, superpostas na ordem decrescente e colocadas em agitador mecânico por dez minutos. Nos grãos da fração areia avaliouse o seu grau de arredondamento e esfericidade. Para tal utilizou-se cerca de 100 grãos de areia, que foram analisados através de uma lupa binocular e comparados visualmente às tabelas de classes de arredondamento e esfericidade de Russel \& Taylor (1937).

As amostras para análises mineralógicas e químicas foram pulverizadas em gral de ágata. As análises mineralógicas foram feitas por difração de raios - $\mathrm{X}$ (DRX), empregando-se um difratômetro Philips, modelo PW 3710, equipado com anodo de cobre (CuKa $1=1,5406 \AA$ ), com cristal monocromador, gerador de tensão e corrente ajustados para $45 \mathrm{kV}$ e $40 \mathrm{~mA}$, respectivamente. Para a identificação dos minerais utilizou-se o software APD (Philips) e o banco de dados do ICDD (International Center for Diffraction Data). As proporções mineralógicas presentes em cada amostra foram calculadas estequiometricamente com base nos minerais identificados por DRX e na composição química total.

A composição química total dos sedimentos (cerca de $5 \mathrm{~g}$ cada) foi determinada através de fusão com metaborato/tetraborato de lítio e solubilização ácida. Em seguida os elementos foram determinados por espectrometria de massa com plasma indutivamente acoplado (ICP-MS).

Com exceção das análises químicas, realizadas nos Actlabs Laboratories - Ltd, Canadá, as demais foram realizados nos laboratórios do Instituto de Geociências da Universidade Federal do Pará.

\section{RESULTADOS E DISCUSSÃO}

Características fisiográficas da paisagem e dos lagos A paisagem estudada consiste em uma baixa planície (altitudes variáveis entre 85 a 95 metros de altitude) onde se desenvolvem inúmeras depressões ocupadas por lagos e brejos. A vegetação está representada por savanas do tipo parque e graminosa. O predomínio de um ou outro tipo está ligado às variações topográficas. Nas áreas de relevo mais baixo, domina savana graminosa, formando os chamados campos limpos. Nos locais mais elevados que geralmente constituem os divisores de drenagem, a savana parque (campos sujos) predomina. Ela apresenta espécies arbustivas de caules retorcidos e folhas grossas a exemplo da Curatella americana (caimbé), Byrsonima crassifolia (murici) e o Anacardium occidentale (caju) (Fig. 2). A Mauritia flexuosa (buriti), palmeira de grande porte, aparece constantemente serpenteando essa paisagem. A Mauritia ocorre às margens de igarapés como mata de galeria, em áreas brejosas quando assume padrões lineares ou entrelaçados para formar as veredas. Estas podem atingir quilômetros de comprimento, e/ou ainda circundar alguns lagos da região (Fig. 3).

Os lagos que juntamente com os brejos e igarapés constituem a drenagem local, aparecem em grande número, são relativamente denso na paisagem (Fig. 4). Suas formas predominantes são goticulares, circulares, elipsoidais e geminadas. Essas formas são determinadas geralmente pelo tipo ou padrão de conexão que determinado lago mantém com as veredas ou igarapés. Os lagos de contorno goticular, por exemplo, aparecem conectados aos fluxos lineares de água superficial, como igarapés e veredas. São, portanto, lagos essencialmente formadores de drenagem (nascentes). A montante das nascentes podem tanto ocorrer isolados, como coalescentes com outros lagos que alimentam a drenagem fluvial (Fig. 5a). Os lagos elipsoidais são freqüentes em campos brejosos, ou assim como os lagos circulares, podem ocorrer isolados. Os lagos em formas geminada resultam da junção de dois ou mais lagos, proporcionado pelo rompimento do divisor d'água, por conta do aumento do nível das águas dos lagos no período chuvoso. Diante da proximidade existente entre
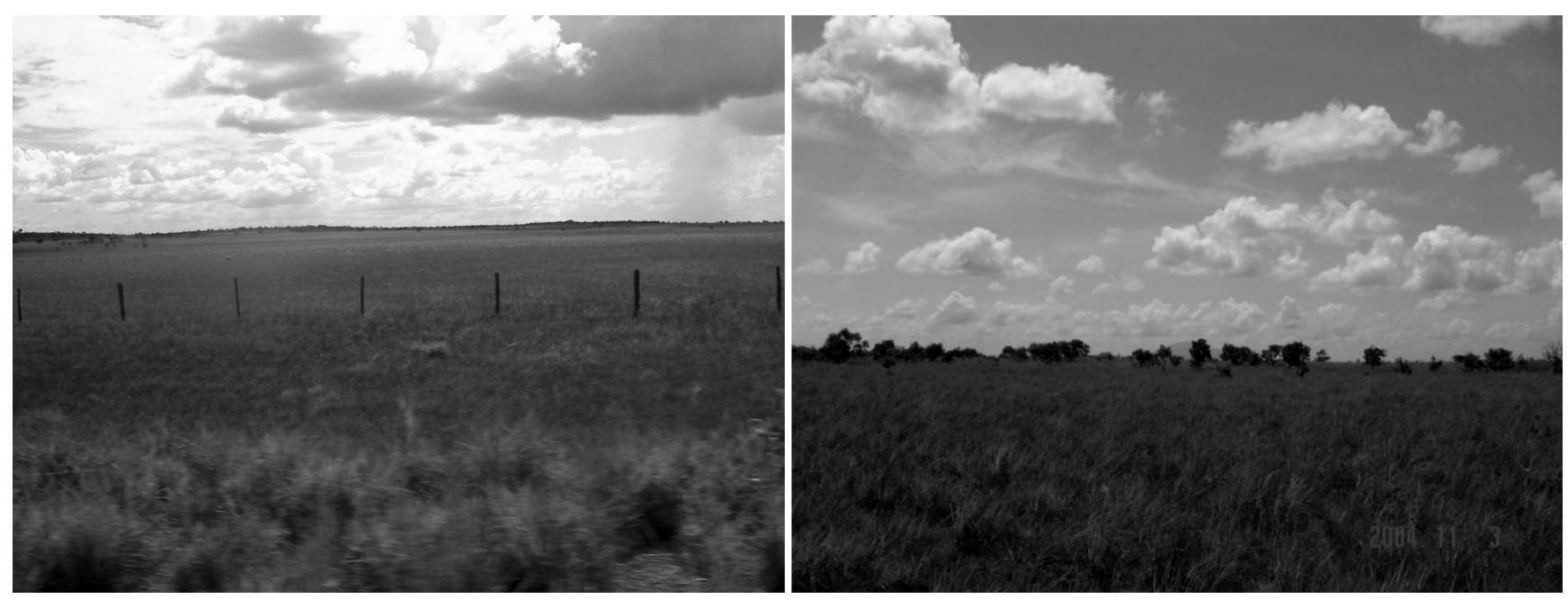

Figura 2 - Cobertura vegetal da área estudada: à esquerda, savana graminosa formando os campos limpos que recobrem as áreas mais planas e baixas; à direita formações de savana parque composta por Curatella americana e Byrsonima crassifolia ocorrendo nas áreas mais elevadas do relevo. 

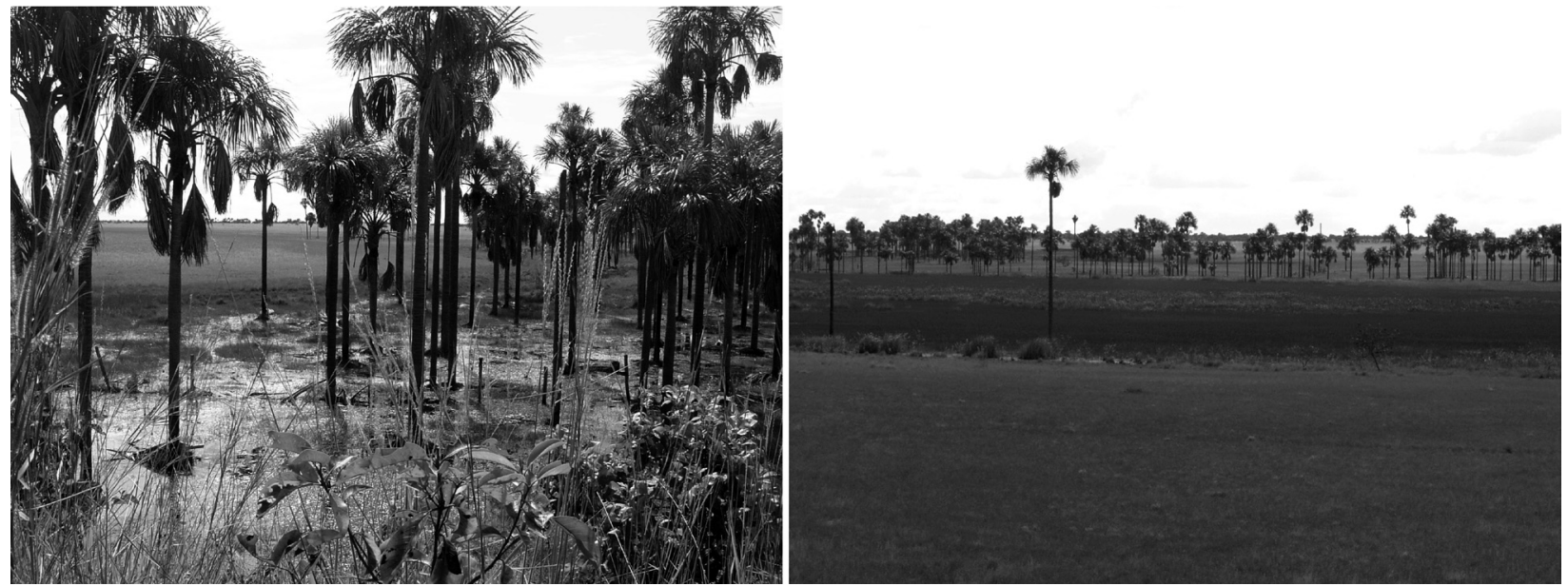

Figura 3 - Paisagem de campos limpos recortada por Mauritia flexuosa, em áreas brejosas como parte de vereda (à esquerda); paisagem graminosa com lago sendo cincundado por Mauritia flexuosa (à direita).

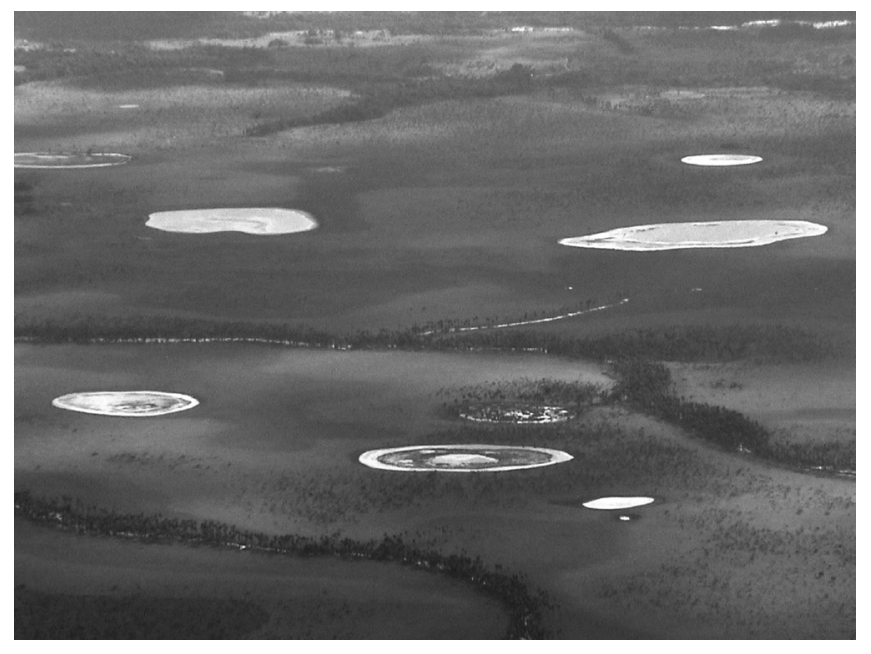

Figura 4 - Vista aérea da paisagem de savanas mostrando a freqüente ocorrência dos lagos. Destaca-se neste cenário o predomínio de lagos circulares e elipsoidais, com macrófitas dispostas em zonas e ainda a presença de zona central, tipo olho d'agua.

suas bacias, passam a formar um único corpo lacustre interinamente (Fig. 5b).

Os lagos estudados são muitos pequenos, com 0,5 a 20 hectares: $62 \%$ deles apresentam área menor que 5 hectares. A profundidade é também pequena, em geral situada entre 0,8 e 2,5 metros (medidas no período chuvoso). O nível d'água desses lagos é sazonalmente controlado. Durante a estiagem cerca de $65 \%$ deles secam completamente, expondo o fundo de suas bacias, ou se reduzem a pequenos núcleos d'água, limitados por círculos brejosos (Fig. 6a). Essa intermitência é atribuída ao longo período de seca (seis meses) a que é submetida essa região do estado de Roraima aliada à pequena profundidade das bacias lacustres. Nesse período os brejos e as veredas também secam e estressam as gramíneas e árvores de Mauritia flexuosa. Na estação chuvosa, com alto índice pluviométrico, ocorre a subida do nível freático, que aflora nas áreas mais baixas, intercepta as depressões lacustres e transforma os campos de gramíneas ressequidas em extensos campos brejosos. Nesse período os lagos sazonais voltam a apresentar significativa lâmina d'água e os perenes duplicam sua área de drenagem. A elevada freqüencia dos lagos e a íntima proximidade entre eles, aliadas à planura do terreno, com estreitas e sutis faixas de divisores d'água, levam a interligação entre vários corpos d'água (brejos, lagos e veredas), e formam uma paisagem semelhante àquela encontrada no Pantanal Matogrossense. (Fig. 6b), aqui conhecida como lavrado.

Os lagos estudados apresentam-se em sua grande maioria intensamente colonizados por macrófitas aquáticas emergentes (ciperáceas) e fixas ao fundo com folhas flutuantes (ninfeáceas). Estas últimas, embora em menor expressão, ocorrem indistintamente em todos os lagos, enquanto que as primeiras se estabelecem conforme a profundidade das bacias lacustres. Nos lagos rasos, a ocupação por estes vegetais é quase completa, exceto em uma pequena zona central. Nos lagos de profundidades mais elevadas ( $>1,5$ metros) as ciperáceas ocupam apenas as zonas de margens, ou estão simplesmente ausentes. A vegetação, portanto apresenta uma distribuição zonada, concêntrica, seguindo o contorno do lago e a morfologia do fundo e da variação de sua profundidade. A zona central, em geral livre de vegetação, denota a parte mais profunda, onde há surgência da água, tipo olho d'agua. Uma elevação concêntrica entre a zona central e as margens do lago, normalmente colonizada por gramíneas, deve ter sido formada pelo movimento borbulhante das águas no local de sua surgência. Este processo remobiliza o material arenoso do substrato sedimentar lançando-o radialmente em todas as direções (Fig. 7), com intensidade decrescente para fora.

\section{Caracterização dos sedimentos dos substratos lacus- tres}

ASPECTOS LITOLÓGICOS E GRANULOMÉTRICOS

Não foram encontrados sedimentos tipicamente lacus- 

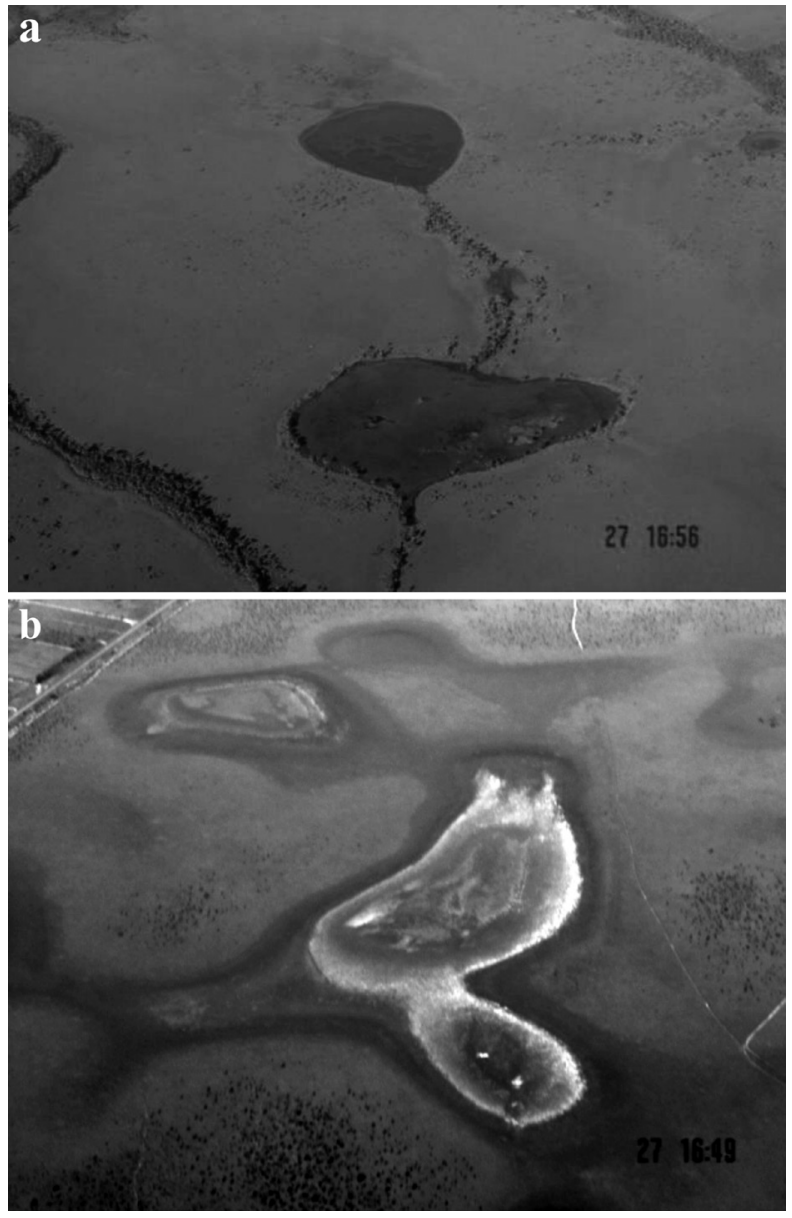

Figura 5 - Principais padrões de lago conectados com a drenagem observados na paisagem. a) lagos goticulares interconectados entre si por uma pequena e estreita vereda e que funcionam como cabeceira de um canal de drenagem de maior extensão (igarapé); b) a junção de duas bacias lacustres originando um lago geminado. tres. Os materiais coletados nas margens e centro dos lagos apresentaram, indistintamente, a predominância da fração arenosa (principalmente areia média e fina). A fração areia variou entre 70 e $85 \%$, enquanto que a fração fina (silte e argila) oscilou entre 15 e 30\%. Os grãos de areia apresentam morfologias variadas, cerca de $40 \%$ são angulosos, 50\% são subangulosos, e os 10 $\%$ restantes são sub-arredondados. Aproximadamente $90 \%$ dos grãos apresentam baixa esfericidade, predominando formas achatadas e alongadas (Fig. 8). Essas características excluem a possibilidade de que sejam de origem eólica, como admitido por Latrubesse \& Nelson (2001) para aqueles da região dos rios Cauamé e Tacutu. Por outro lado, essas características são comparáveis àquelas descritas por Montalvão et al. (1975) para os sedimentos da Formação Boa Vista, o substrato geológico dos lagos estudados.

COMPOSIÇÃO QUÍMICO - MINERALÓGICA Os sedimentos de substrato lacustre são constituídos predominantemente por quartzo e pequenas quantidades de caulinita. O domínio do quartzo nestes sedimentos é confirmado pela sua composição química: domínio de $\mathrm{SiO} 2$, que varia de 81 a \% e $97 \%$ e valores muito baixos de $\mathrm{Al}_{2} \mathrm{O}_{3}\left(0,48\right.$ a 7,54\%), $\quad \mathrm{Fe}_{2} \mathrm{O}_{3}$ e $\mathrm{TiO}_{2}$ ocorrem em pequenas quantidades variando de $0,06 \%$ a $0,42 \%$, e de $0,23 \%$ a $0,81 \%$, respectivamente. Os demais constituintes $\left(\mathrm{MnO}, \mathrm{CaO}, \mathrm{MgO}, \mathrm{Na}_{2} \mathrm{O}, \mathrm{K}_{2} \mathrm{O}\right.$ e $\mathrm{P}_{2} \mathrm{O}_{5}$ ), apresentaram-se em valores abaixo do limite de detecção (Tab. 1).

Os teores de quartzo alcançam assim 72,3 a $96,5 \%$, enquanto que os de caulinita são inferiores a $10 \%$. Somente as amostras LCI 20-40 e LCC 20-40 apresentaram teores mais elevadas de caulinita, (Tab. 2), representadas por maior fração granulométrica de argila. Os teores de goethita oscilam entre 0,1 e $0,5 \%$ e os de rutilo e/ou anatásio estão na faixa percentu-
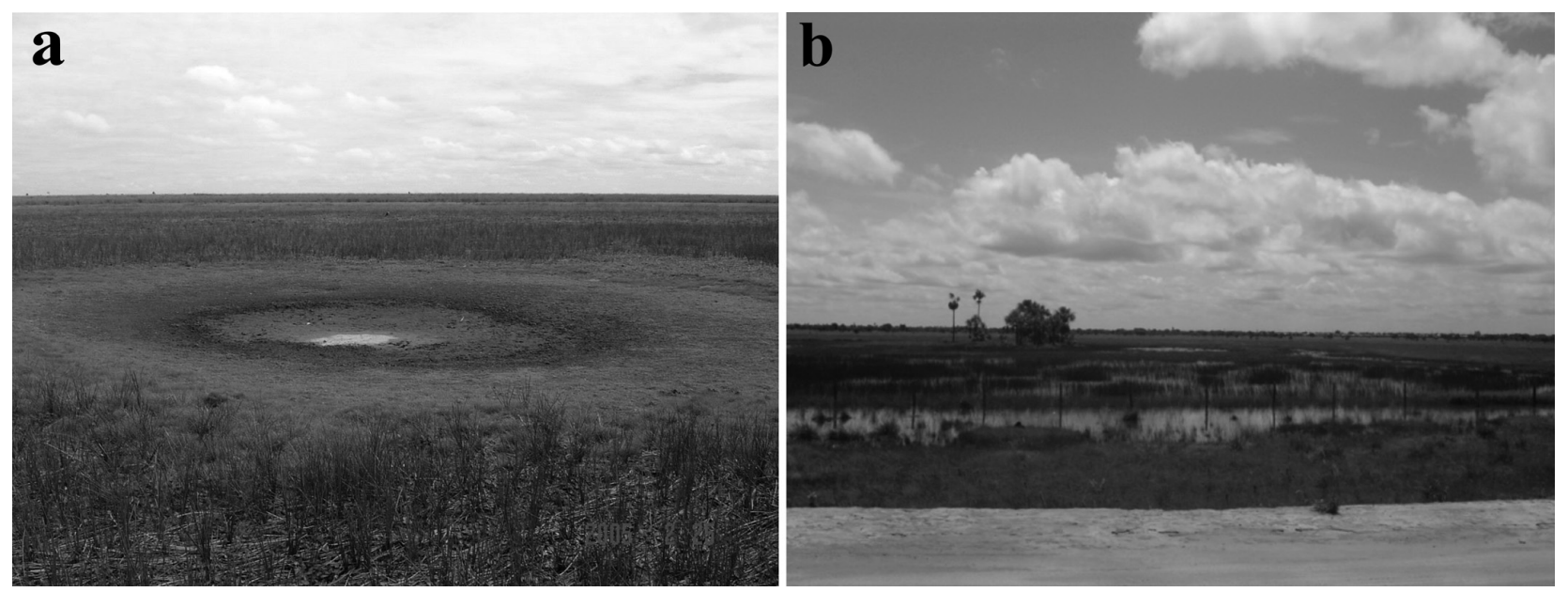

Figura 6 - Aspectos da paisagem do lavrado em estações climáticas distintas. a) período de estiagem quando lagos, veredas e brejos secam quase completamente e dezenas de depressões lacustres secas ou semi-secas aparecem expondo ofundo de suas bacias. b) no período chuvoso os campos de savana são invadidos pelas águas pluviais e freáticas que fazem transbordar lagos e outros corpos hídricos transformando a região em um grande alagado. 

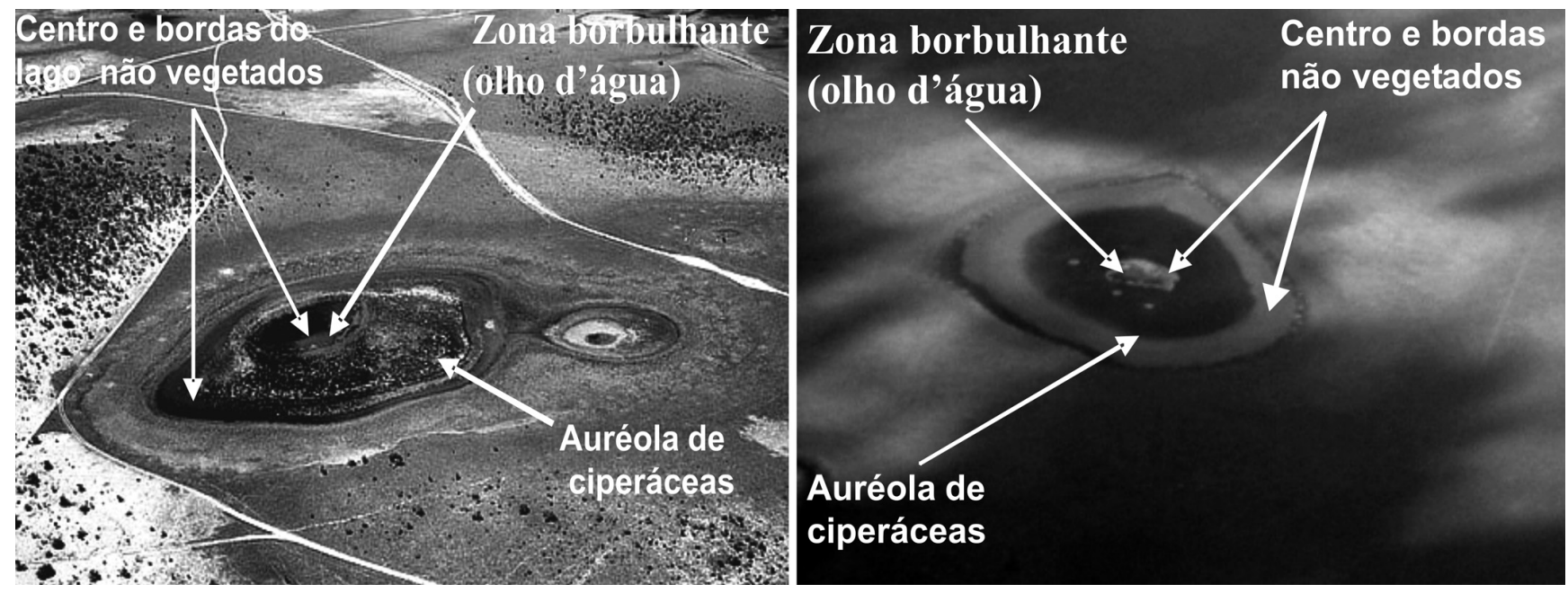

Figura 7 - Lago geminado (à esquerda) e goticular (à direita,) ambos colonizados por auréolas concêntricas de ciperáceas cercando o olho ou nascente do lago (Fotos: Margi Moss - Projeto Brasil das Águas e Marcondes Lima da Costa respectivamente).
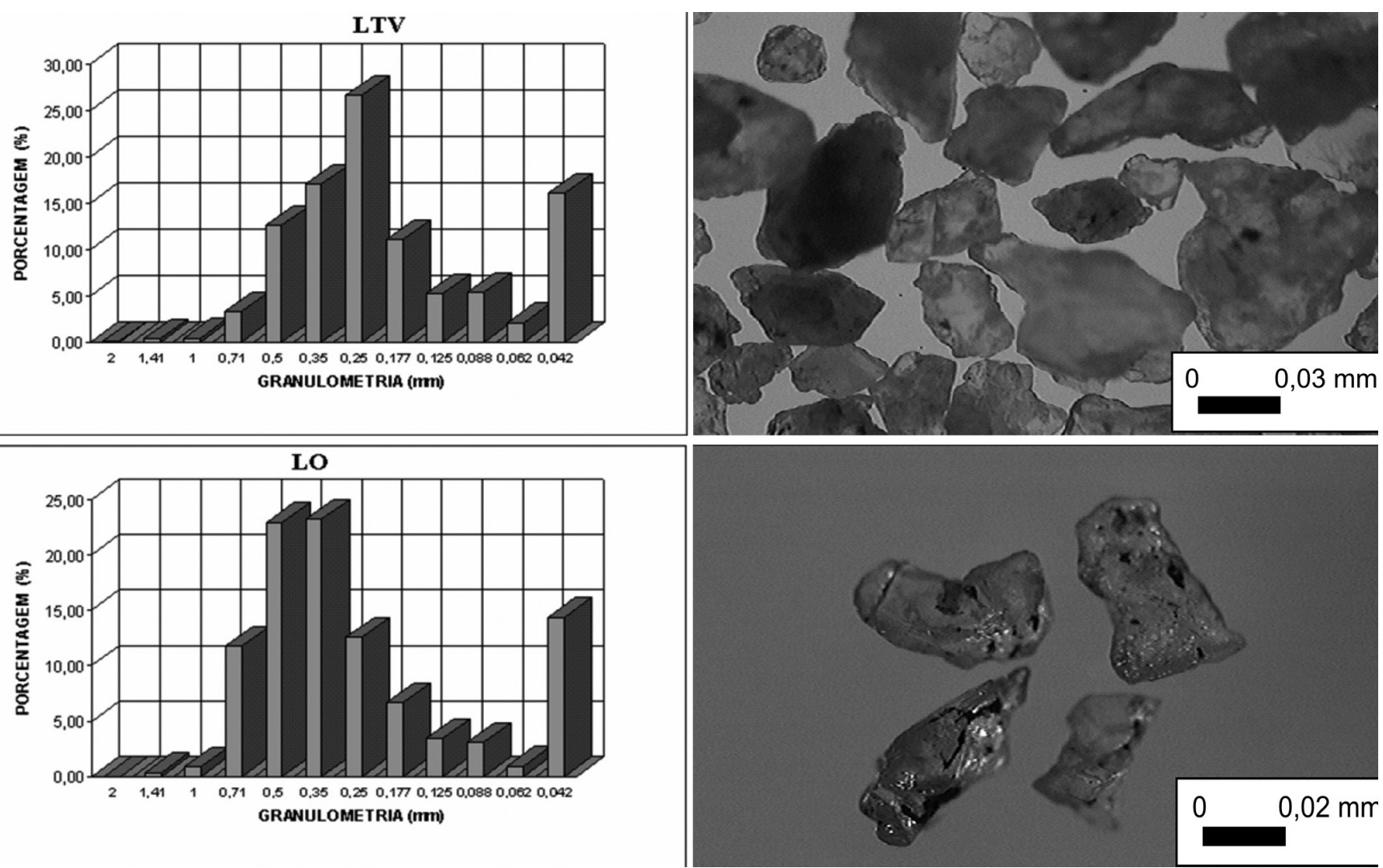

Figura 8 - À esquerda histogramas mostram a predominância de areia média e fina nos sedimentos de substrato lacustre, enquanto que a foto à direita exibe a morfologia angulosa e subangulosa e a baixa esfericidade desses grãos de areia.

al de 0,3 a $0,8 \%$. Estes minerais pelo fato de estarem em concentrações tão pequenas não foram identificados por DRX, entretanto, foram inferidos em função da presença de $\mathrm{Fe}_{2} \mathrm{O}_{3}$ e $\mathrm{TiO}_{2}$ nas amostras. Essa composição mineralógica é compatível com aquela dos sedimentos à Formação Boa Vista, que segundo Carneiro Filho (1991) é constituída por estes minerais: quartzo, caulinita, goethita e rutilo/anatásio.
Os teores de quartzo encontram-se mais elevados no intervalo de $0-20 \mathrm{~cm}$ de profundidade, enquanto caulinita, goethita e anatásio/rutilo se concentram do que naquele de 20-40. Este padrão é compatível com perfis de solos tropicais, ácidos e com matéria orgânica. . Todavia, pode sugerir ambientes sob regência de processos de podzolização dada a presença abundante do quartzo, em detrimento de caulinita e goethita, 
Tabela 1 - Composição química (\% em peso) de amostras de sedimentos do substrato dos lagos comparados com aqueles da planície de inundação do Rio Branco.

\begin{tabular}{l|c|c|c|c|c|c|c|c|c|c|c|c}
\hline Amostras & $\mathrm{SiO}_{2}$ & $\mathrm{Al}_{2} \mathrm{O}_{3}$ & $\mathrm{Fe}_{2} \mathrm{O}_{3}$ & $\mathrm{MnO}$ & $\mathrm{MgO}$ & $\mathrm{CaO}$ & $\mathrm{Na}_{2} \mathrm{O}$ & $\mathrm{K}_{2} \mathrm{O}$ & $\mathrm{TiO}_{2}$ & $\mathrm{P}_{2} \mathrm{O}_{5}$ & PF & TOTAL (\%) \\
\hline LO 0-20 & 92,77 & 2,87 & 0,13 & 0,002 & $<0,01$ & $<0,01$ & $<0,01$ & $<0,01$ & 0,29 & $<0,01$ & 2,9 & 98,93 \\
\hline LO 20-40 & 94,03 & 3,07 & 0,11 & 0,002 & $<0,01$ & 0,01 & $<0,01$ & $<0,01$ & 0,29 & 0,01 & 1,37 & 99,42 \\
\hline LAP 0-20 & 97,08 & 0,48 & 0,06 & 0,003 & $<0,01$ & $<0,01$ & $<0,01$ & $<0,01$ & 0,23 & $<0,01$ & 1,53 & 99,37 \\
\hline LAP 20-40 & 96,17 & 0,80 & 0,06 & 0,005 & $<0,01$ & $<0,01$ & $<0,01$ & $<0,01$ & 0,25 & 0,01 & 2,09 & 99,39 \\
\hline LCI 0-20 & 94,48 & 2,65 & 0,19 & 0,003 & $<0,01$ & $<0,01$ & 0,04 & 0,02 & 0,27 & 0,02 & 1,64 & 99,32 \\
\hline LCI 20-40 & 86,23 & 7,46 & 0,6 & 0,007 & $<0,01$ & $<0,01$ & 0,06 & $<0,01$ & 0,60 & 0,01 & 3,62 & 98,53 \\
\hline LTV 0-20 & 93,59 & 2,52 & 0,28 & 0,002 & $<0,01$ & $<0,01$ & 0,03 & $<0,01$ & 0,26 & 0,01 & 2,78 & 99,44 \\
\hline LTV 20-40 & 91,73 & 3,82 & 0,39 & 0,002 & $<0,01$ & $<0,01$ & 0,06 & $<0,01$ & 0,34 & 0,02 & 2,91 & 99,35 \\
\hline LCC 20-40 & 81,26 & 7,54 & 0,42 & 0,007 & $<0,01$ & $<0,01$ & 0,05 & 0,07 & 0,81 & 0,02 & 8,52 & 98,57 \\
\hline Média & 91,92 & 3,46 & 0,24 & 0,03 & - & - & - & - & 0,37 & - & 3,04 & - \\
\hline $\begin{array}{c}\text { Rio Branco } \\
\text { (média) }\end{array}$ & 55,6 & 25,4 & 3,43 & 0,16 & 0,32 & 0,03 & 0,08 & 1,19 & 0,79 & 0,03 & 12,2 & \\
\hline
\end{tabular}

PF - Perda ao fogo

Tabela 2 - Composição mineralógica (\% em peso) obtida por cálculos estequiométricos em amostras dos sedimentos dos lagos estudados.

\begin{tabular}{c|c|c|c|c|c|c}
\hline Amostras & Quartzo & Caulinita & Goethita & Rutilo/Anatásio & M O. & Total (\%) \\
\hline LO 0-20 & 89,3 & 7,3 & 0,1 & 0,3 & 1,9 & 98,9 \\
\hline LO 20-40 & 90,4 & 7,8 & 0,1 & 0,3 & 0,3 & 98,9 \\
\hline LAP 0-20 & 96,5 & 1,2 & 0,1 & 0,2 & 1,3 & 99,3 \\
\hline LAP 20-40 & 95,2 & 2 & 0,1 & 0,3 & 1,8 & 99,4 \\
\hline LCI 0-20 & 91,3 & 6,7 & 0,2 & 0,3 & 0,7 & 99,2 \\
\hline LCI 20-40 & 77,3 & 19 & 0,7 & 0,6 & 1 & 98,6 \\
\hline LTV 0-20 & 90,6 & 6,4 & 0,3 & 0,3 & 1,9 & 99,5 \\
\hline LTV 20-40 & 87,2 & 9,7 & 0,4 & 0,3 & 1,6 & 99,2 \\
\hline LCC 20-40 & 72,3 & 19,2 & 0,5 & 0,8 & 5,9 & 98,7 \\
\hline Média & 87,7 & 8,8 & 0,3 & 0,4 & 1,8 & - \\
\hline
\end{tabular}

M O - Matéria orgânica

os quais, nos referidos ambientes, são decompostos e lixiviados das camadas superficiais do solo (Horbe et al. 2003). Isto é confirmado pela alta abundancia de $\mathrm{SiO} 2$ e pobreza em $\mathrm{A} 12 \mathrm{O} 3$ e $\mathrm{Fe} 2 \mathrm{O} 3$ e demais elementos ( $\mathrm{MnO}, \mathrm{CaO}, \mathrm{MgO}, \mathrm{Na} 2 \mathrm{O}, \mathrm{K} 2 \mathrm{O}$ e P2O5) (Tab 1) nas amostras mais superficiais. Esta interpretação é reforçada pelas condições de hidromorfismo reinantes nestas áreas, principalmente durante o período chuvoso. São condições típicas de podzolização tropical segundo Krauskopf (1972).

CORRELAÇÃO MINERALÓGICA COM OS SEDIMENTOS DA PLANÍCIE DE INUNDAÇÃO DO RIO $B R A N C O$ Os sedimentos da planície de inundação do rio Branco são constituídos por quartzo, caulinita e illita. Portanto, bem distintos daqueles dos substratos lacustres, constituídos apenas de quartzo e caulinita (Fig. 9). A composição química média destes sedimentos caacteriza-se pela predominância de $\mathrm{SiO} 2,(55,60 \%)$ e de Al2O3 $(25,4 \%)$, além de Fe2O3 $(3,43)$ e K2O $(1,19)$. Os demais elementos apresentaram-se em valores inferiores a $1 \%$ (Tab. 1). São, portanto quimicamente bem distintos dos materiais que constituem os substratos dos lagos aqui investigados, com domínio quase isolado de $\mathrm{SiO} 2$ e pobres em metais alcalinos, como K. Os sedimentos da bacia de inundação do rio Branco são, portanto muito mais ricos em argila, incluindo não somente a caulinita como illita, e quimicamente ricas em $\mathrm{K}$, e adequadas para a produção de cerâmica vermelha. Assim os sedimentos lacustres investigados não fazem parte daqueles da planície de inundação do rio Branco.

Aspectos físico-químicos das águas lacustres As águas dos lagos analisados apresentaram valores de temperatura entre 30 e $34{ }^{\circ} \mathrm{C}$, refletindo as condições térmicas típicas do clima da região (Awi na classificação de Köppen), que pode apresentar temperatura de até $42{ }^{\circ} \mathrm{C}$. O pH é ácido, variando entre 5,0 e 6,0. Três lagos urbanos mostraram valores de $\mathrm{pH}$ próximo de neutro a ligeiramente básico $(6,57$ e 8,20) (Fig. 10). Estes estão situados em áreas de intensa e desordenada ocupação urbana, onde ainda não há o fornecimento dos serviços básicos (água tratada, rede de esgotos, coleta de lixo etc.). Por conta disso são utilizados pela população, para os mais diversos fins, tais como: la- 

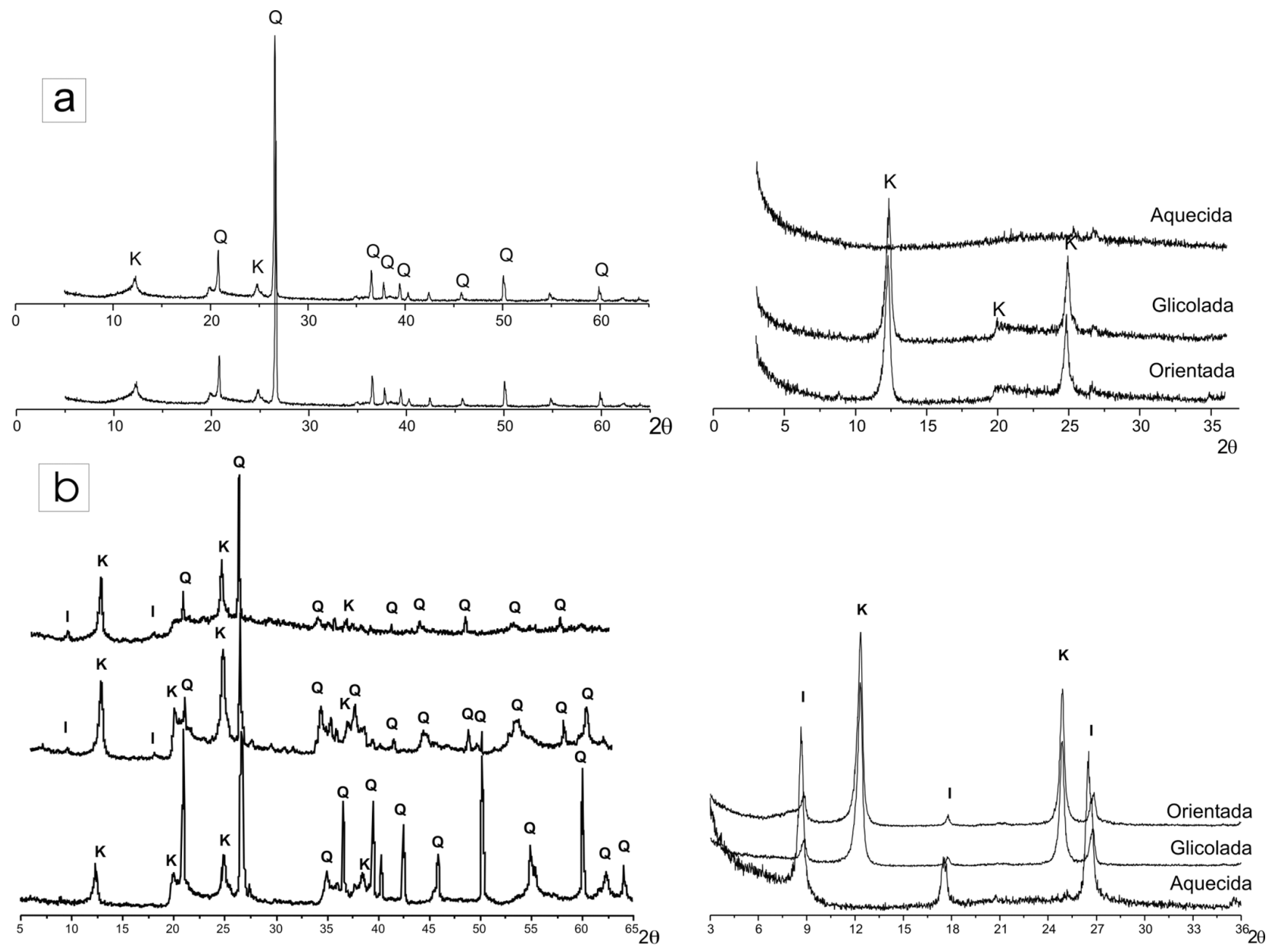

Figura 9 - Difratogramas de raios - $x$ de amostra total e lâmina orientada comparando a mineralogia dos sedimentos de substrato lacustres (a) com aqueles encontrados na planície de inundação do rio Branco (b). (Legenda: Q- quartzo, $K$ - caulinita e I - illita).

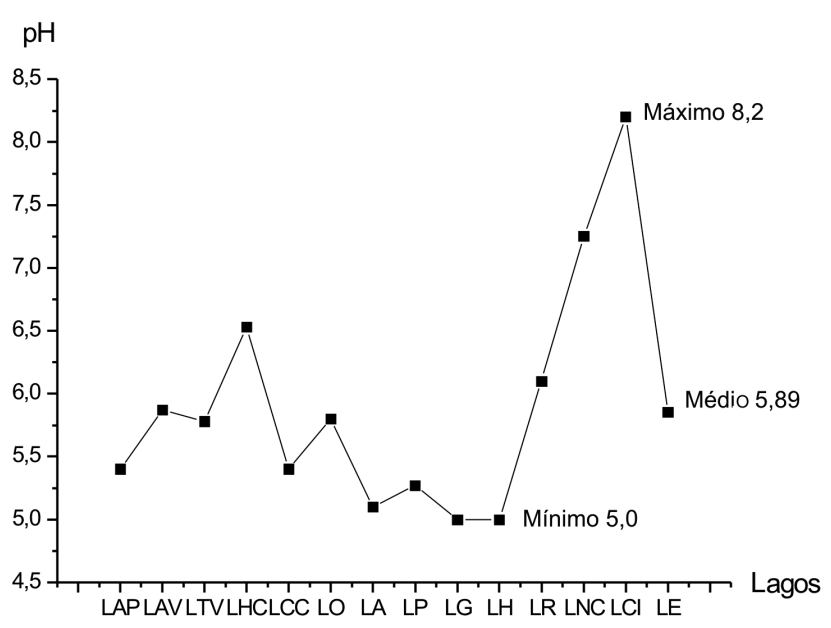

Figura 10 - Distribuição dos valores de pH na água dos lagos. Notar que os valores mais elevados foram encontrados nos lagos: Hélio Campos (LHC), Cidade (LCI) e Nova Cidade (LNC), os quais estão situados em áreas urbanas. vagem de roupas e utensílios domésticos, lançamento de efluentes domésticos, balneário e fonte de alimento (pesca). Os saponáceos e detergentes utilizados na lavagem de roupas, e os efluentes domésticos (urina, excrementos humanos e de outros animais, etc.), são ricos em nutrientes ( $\mathrm{N}, \mathrm{P}$ e $\mathrm{K})$, que ao fertilizarem as águas, aceleram o metabolismo vegetal e promovem a proliferação da vegetação aquática em geral (Esteves, 1998)). De acordo com Schaffer (1985) os processos produtivos (fotossintéticos) podem elevar o $\mathrm{pH}$ das águas, uma vez que reduzem a disponibilidade do gás carbônico (responsável pela acidificação) no meio hídrico. Dessa forma, atribuem-se os altos valores de $\mathrm{pH}$, encontrados nestes lagos, à intensa atividade de macrófitas aquáticas que ocupam parcelas significativas destes lagos urbanos. Elas estão representadas por diversas famílias (ciperáceas, ninfeáceas, convolvuláceas, onagráceas e ponteridáceas), ao contrário dos demais lagos estudados não afetados pela atividade urbana, onde as ciperáceas são dominantes.

A condutividade elétrica variou entre 4 e $14 \mu \mathrm{S} /$ $\mathrm{cm}$, refletindo as baixas concentrações de sólidos totais dissolvidos, cujos valores variaram entre 2,0 e 
7,0 mg/L (Fig. 11). Os mais elevados valores foram obtidos nos lagos: Nova Cidade (LNC), Cidade (LCI), e no lago das Hortas (LH). Os dois primeiros lagos são coincidentemente os mesmos que apresentaram valores elevados de $\mathrm{pH}$, relacionados às atividades antrópicas. Os valores muito baixos de condutividade elétrica mostram que as águas dos lagos provém de terrenos relativamente pobres em íons como, $\mathrm{Ca}+, \mathrm{Mg} 2+, \mathrm{K}+\mathrm{e} \mathrm{Na}+$, neste caso representados pelos sedimentos da Formação Boa Vista, como já foi demonstrado. Estes valores de CE estão na ordem de grandeza para esta porção da região Amazônica, que varia de 10 a $20 \mu \mathrm{S} / \mathrm{cm}$.

O oxigênio dissolvido se encontra entre 4,0 e $5,7 \mathrm{mg} / \mathrm{L}$ excetuando-se o lago Nova Cidade que apresentou um valor de $2,2 \mathrm{mg} / \mathrm{L}$ (Fig. 12). Seus baixos valores possivelmente refletem a densa colonização por macrófitas aquáticas (Fig. 13), que cobrem cerca de 80 $\%$ de sua bacia. Ao se decomporem consome o oxigênio dissolvido na água, contribuindo assim, para a sua diminuição no meio hídrico. Da mesma forma agem as cargas orgânicas (lixo doméstico, cadáveres de animais etc.) lançadas neste lago.

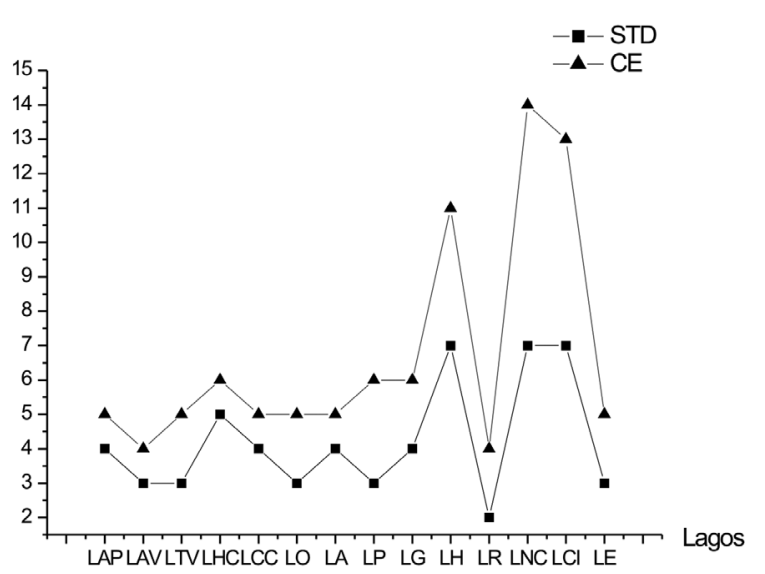

Figura 11 - Comparação entre valores de condutividade elétrica - CE $(\mu \mathrm{S} / \mathrm{cm})$ e sólidos totais dissolvidos - STD ( $\mathrm{mg} / \mathrm{L})$ mensurados nas águas dos lagos.

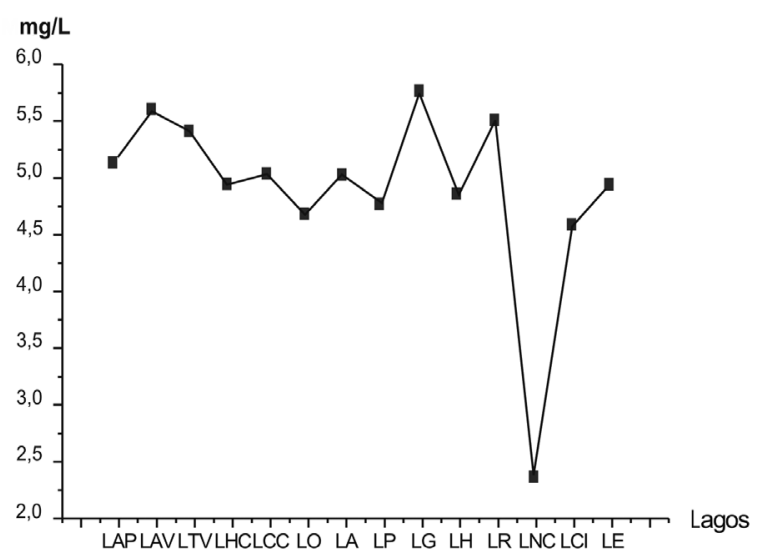

Figura 12 - Distribuição dos valores de oxigênio dissolvido ( $\mathrm{mg} / \mathrm{L})$ nas águas dos lagos estudados, com destaque para o lago Nova Cidade (LNC) que apresentou o mais baixo valor $(2,2 \mathrm{mg} / \mathrm{L})$.

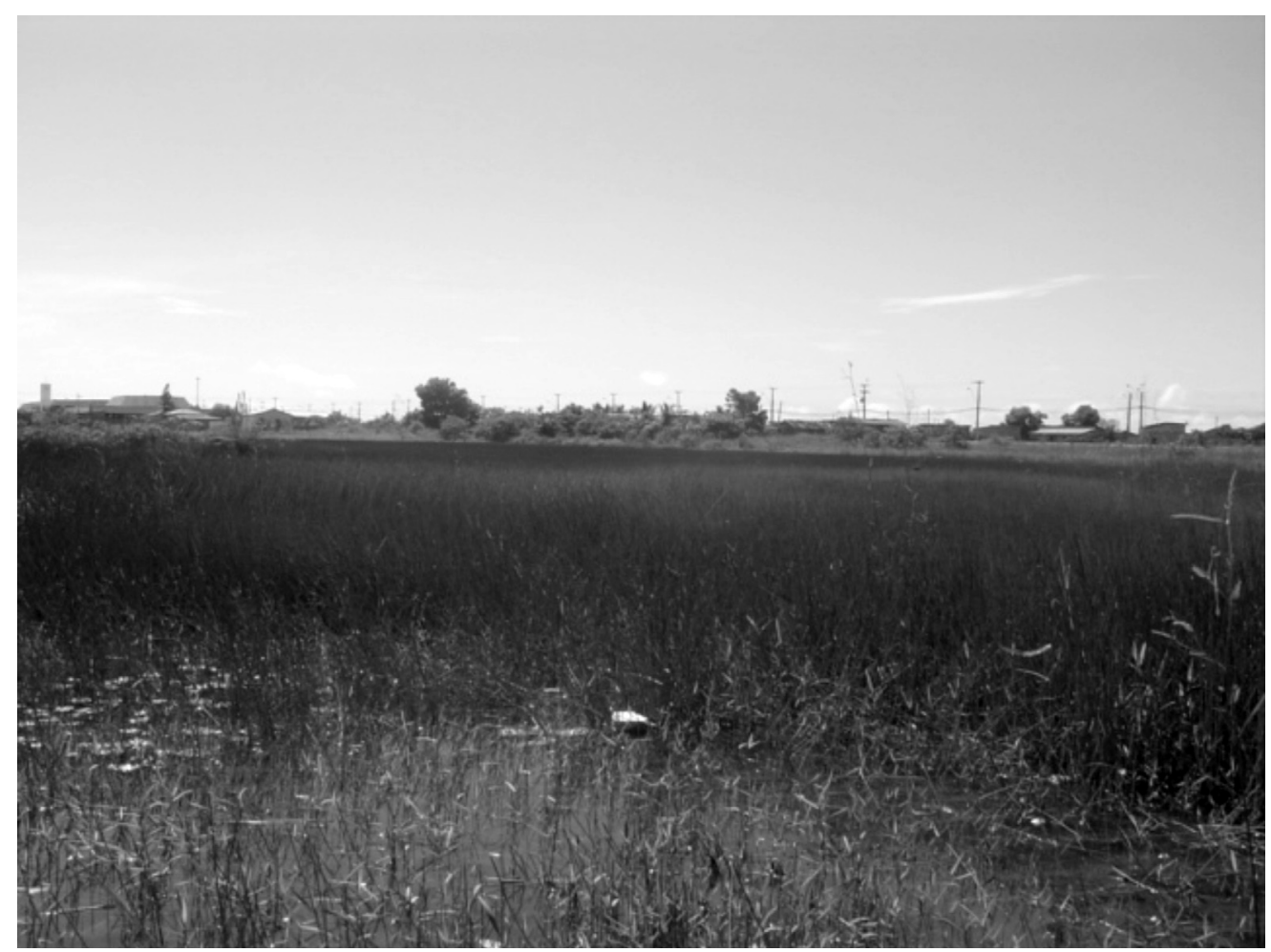

Figura 13 - Vista parcial do lago Nova Cidade mostrando a sua intensa ocupação por macrófitas aquáticas. 
CONCLUSÕES Os lagos estudados inserem-se em uma unidade fisiográfica atípica no âmbito das paisagens florestais observadas na região amazônica: uma extensa superfície aplanada coberta por savanas arbóreas a graminosas. É uma feição única e típica da porção nordeste do estado de Roraima. Seus lagos, ao contrário da maioria dos lagos do território brasileiro e em particular do amazônico, não são produtos de atividades fluviais. Pertencem, no entanto, à bacia hidrográfica do rio Branco, e estão localizados à montante de pequenos cursos d'água (igarapés) e veredas, quando desempenham o papel de nascentes.

Os lagos estudados não apresentam sedimentos tipicamente lacustres. O seu entorno e o substrato é formado por material arenoso, quartzoso, branco manchado por matéria orgânica, com características de solos tipo podzol, derivados da formação Boa Vista. A ausência de sedimentos lacustres, por outro lado, sugere que sejam bem mais jovens, que os outros lagos encontrados no estado de Roraima, como Caracaranã, de grande porte, localizado no extremo nordeste do Estado, formado há aproximadamente 9.000 anos A.P. (Simões Filho et al, 1997).

As características granulométricas e morfológicas excluem a possibilidade de que sejam de origem eólica. Não há qualquer evidência desta atividade, ao contrário do que concluiu Latrubesse \& Nelson (2001) para alguns lagos situados em áreas próximas à deste estudo.

As análises granulométricas aliadas às análises mineralógicas e químicas sugerem que os sedimentos estudados derivaram da Formação Boa Vista, e não tem qualquer relação com os sedimentos da planície de inundação do rio Branco. Os sedimentos da Formação Boa Vista, o substrato direto dos mesmos, têm espessura máxima de 15 metros (Reis et al. 2001) e estão sobreposto ao embasamento cristalino. Na formação Boa Vista está o principal lençol freático da região estudada. Durante o período chuvoso a infiltração das águas pluviais provoca a súbita elevação do nível freático que intercepta as áreas deprimidas do terreno ou aflora na superfície dando origem aos lagos e brejos.

Os parâmetros físico-químicos mostraram significativas variações nas águas dos lagos situados em áreas urbanas, sendo indicadores do forte impacto antrópico representado por lançamento de efluentes domésticos no entorno dos lagos, e por vezes dentro do próprio lago, e utilização das águas para lavagem de roupas. Portanto, a acelerada urbanização não planejada da cidade de Boa Vista está contribuindo para o desaparecimento precoce destes lagos, cuja importância reside não apenas por sua beleza cênica, mas, fundamentalmente, por representar importante fonte de recursos hídricos.

Agradecimentos Ao $\mathrm{CNPq}$ pelo apoio financeiro através do projeto: Geoquímica de Sedimentos e Solos Atuais, como Parâmetros de Avaliação da Ação do Intemperismo Tropical na Amazônia: Importância Geológica - Arqueológica e Sócio-Econômica - GEOSEDINTAMA, (processo 471109/2003-7), pela bolsa de mestrado concedida à primeira autora e de produtividade de pesquisa ao segundo autor.

\section{Referências}

Absy M. L., Prance G. T., Servant M., Miranda I. S. 1997. Registros Palinólogicos em Sedimentos do Holoceno e Vegetação Atual de Roraima. In: R.I. Barbosa, E.J.G. Ferreira, E.G. Castellon (Orgs.) Homem, Ambiente e Ecologia no estado de Roraima. INPA, Manaus. p. 462479.

Barbosa O. \& Ramos J.R. 1959. Território de Rio Branco, aspectos principais da geomorfologia, da geologia e das possibilidades minerais de sua zona setentrional. Bol. Div. Geol. Miner, 196:1-49.

Behling H. \& Costa M. L. 2000. Holocene environmental changes from the rio Curuá record in the Caxiuanã region, eastern Amazon basin. Quaternary Research, 53: 369-377.

Behling H. \& Costa M.L. 2001. Holocene vegetational and coastal environmental changes from the Lago Crispim record in northeastern Pará State, eastern Amazonia. Review of Palaeobotany and Palynology, 114:145-155.

Behling H., Keim G., Irion G., Junk W., Melo J. N. 2001. Holocene environmental changes in the Central Amazon Basin inferred from Lago Calado. Palaeogeography, $\mathrm{Pa}$ laeoclimatology, Palaeoecology, 173: 87-101.

Bush M.B., Miller M.C., De Oliveira P.E., Colinvaux P.A. 2002. Orbital forcing signal in sediments of two Amazo- nian lakes. J. Paleolimnology, 27:341-352.

Bush M.B., De Oliveira P.E., Colinvaux P.A., Miller M.C., Moreno J.E. 2004. Amazonian paleoecological histories: one hill, three watersheds Palaeogeography, Palaeoclimatology, Palaeoecology, 214:359-393

Carneiro Filho A. 1991. Contribution to the study of the forest - savanna mosaic in the area of Roraima, nothern Amazon basin. Dissertation of Master. Netherlands. International Institute for Aerospace Survey and Earth Sciences, 116p.

Carvalho P., Bini L.M., Thomaz M.S., Oliveira L.G., Robertson B., Tavechio W.L.G., Darwisch A. 2001. Comparative limnology of South American floodplain lakes and lagoons. Acta Scientiarum, 23:265-273.

Cordeiro R.C., Turcq B., Suguio K., Ribeiro C.V., Silva A.O., Sifeddine A., Martin L. 1997. Holocene environmental changes in Carajas Region (Pará, Brazil) recorded by Lacustrine Deposits. Verh. Int. Verein. Limno., 26:814817.

Costa M.L. 1991. Aspectos geológicos dos lateritos da Amazônia. Revista Brasileira de Geociências, 21:146-160.

Costa J.A.V. 1999. Tectônica da Região Nordeste de Rorai$m a$. Tese de doutoramento, Centro de Geociências, Universidade Federal do Pará, 323p. 
Correa S.L. \& Costa M.L. 1997. Mineralogia das crostas lateríticas ferruginosas de Seis Lagos (Amazonas). Revista Brasileira de Geociências, 16:141-156.

Costa M.L., do Carmo M.S., Behling H. 2005. Mineralogia e geoquímica de sedimentos lacustres com substrato laterítico na Amazônia brasileira. Revista Brasileira de Geociências, 35:165-176.

Esteves F. A. 1998. Fundamentos de Limnologia. Rio de Janeiro. Interciência/ FINEP, 575p.

Franco E.M.S., Del'arco J.O., Rivetti M. 1975. Folha NA.20 Boa Vista e parte das Folhas NA.21 Tumucumaque, NB.20 Roraima e NB.21. Projeto Radambrasil: Geomorfologia, Rio de Jnaeiro, DNPM, p.139-180.

Hess L.L., Melack J.M., Evlyn M.L.M., Novo C.C.F., Barbosa M.G. 2003. Dual-season mapping of wetland inundation and vegetation for the central Amazon basin. Remote Sensing of Environment. 87:404-428.

Horbe A.M.C., Horbe M.A., Suguio K. 2003. A origem dos depósitos de areias brancas no nordeste do estado do Amazonas. Rev. Brasileira de Geociências, 334:41-50.

Irion G., Bus M.B., Nunes de Mello J.A., Stüben D., Neumann T., Müller G., Morais J.O., Junk J.W. 2006. A multiproxy palaeoecological record of Holocene lake sediments from the Rio Tapajós eastern Amazonia. $P a$ laeogeography, Palaeoclimatology, Palaeoecology, 240: 523-535

Junk W.J. 1980. Áreas Inundáveis - Um desafio para Limnologia. Acta Amazônica, 10:775-795.

Junk W.J. 1997. The Central Amazon Floodplain: ecology of a pulsing system. Berlin, Springer Verlag, Ecological Studies, vol. 126, 525 p.

Krauskopf K.B. 1972. Introdução à Geoquímica I. São Paulo, Polígono, 293p.

Latrubesse E.M. \& Nelson B.W. 2001. Evidence for Late Quaternary Aeolian Activity in the Roraima-Guyana Region. Rev. Catena, 43:63-80.

Melack J. M. \& Fisher T.R., 1990. Comparative limnology of tropical floodplain lakes with an emphasis on the central Amazon. Acta Limnologica Brasiliensi, 3:1-48.

Melo A.F.F., Santos A.J., Cunha M.T.P., Campos M.J.F., D'antona R.J.G., Damião R.N. 1978. Projeto Molibdênio em Roraima. Manaus, Relatório DNPM/CPRM, p. 389-400.

Mertes L.A.K. 1994. Rates of flood-plain sedimentation on the central Amazon River. Geology, 22:171-174.

Miranda I.S. \& Absy M.L. 1997. A Flora Fanerogâmica das Savanas de Roraima. In: R.I. Barbosa, E.J.G. Ferreira, E.G. Castellon (Orgs.) Homem, Ambiente e Ecologia no estado de Roraima. Manaus, INPA, p. 445-453.

Montalvão R.M.G., Muniz M.B., Issler R.S., Dalll'agnol R., Lima M.I.C., Fernandes P.E.C.A., Silva G.G. 1975. Geologia do Território Federal de Roraima. In: DNPM, Conferência Geológica Interguianas, 10, Belém, Anais, p. 198-217.

Moreira-Turcq P., Jouanneau J.M., Turcq B., Seyler P., Weber O., Guyot J.L. 2004. Carbon sedimentation at Lago
Grande de Curuai, a floodplain lake in the low Amazon region: insights into sedimentation rates. Palaeogeography, Palaeoclimatology, Palaeoecology,. 214:27-40.

Moss G. \& Moss G. 2005. Projeto: O Brasil das Águas. Disponível em http://www.brasildasaguas.com.br. Acessado em 9 mar 2005.

Reis N.J., Faria M.S.G., Maia M.A.M. 2001. O Quadro Cenozóico da Porção Norte-Oriental do estado de Roraima. In: SBG, Simpósio de Geologia da Amazônia, 7, Belém, Atas, p. 44-47.

Russel R.D. \& Taylor R.E. 1937. Roundness and Shape of Mississipi River Sands. Journal of Geology, 45:225267.

Schaffer A. 1985. Fundamentos de Ecologia e Biogeografia das Águas Continentais. Porto Alegre, ed. UFRGS, $532 \mathrm{p}$.

Sifeddine A., Martin L., Turcq B., Volkmer Ribeiro C., Soubiés F., Campello R.C., Suguio K. 2001. Variations of the Amazonian rainforest environment a sedimentological record covering 30,000 years. Palaeogeography. Palaeoclimatoogy. Palaeoecology, 168:221-235.

Sifeddine A., Wirrmann D., Albuquerque A.L.S., Turcq B., Cordeiro R.C., Gurgel M.H.C., Abrão J.J. 2004. Bulk composition of sedimentary organic matter used in palaeoenvironmental reconstructions: examples from the tropical belt of South America and Africa. Palaeogeography, Palaeoclimatology, Palaeoecology, 214:41-53.

Simões Filho F., Turcq B., Carneiro Filho A., Souza A.G. 1997. Registros sedimentares de lagos e brejos dos campos de Roraima: Implicações paleoambientais ao longo do Holoceno. In: R.I. Barbosa, E.J.G. Ferreira, E.G. Castellon (Orgs.) Homem, Ambiente e Ecologia no estado de Roraima. Manaus, INPA, p. 295-302.

Sioli H. 1984. The Amazon and its main affluents: Hydrology, morphology of the rivers courses, and river types. In: Sioli H. (ed.) The Amazon-Limnology and landscape ecology of a mighty tropical river and its basin. Netherlands, Junk Publishers, 580 p.

Sippel S.J., Hamilton, S.K., Melack, J.M., 1992. Inundation area and morphometry of lakes on the Amazon River floodplain, Brazil. Arch. Hydrobiol., 123:385-400.

Turcq B., Albuquerque A.L.S., Cordeiro R.C., Siffeddine A., Simões Filho F.F.L., Souza A.G., Abrão J.J. Oliveira F.B.L., Silva A.O., Capitâneo J. 2002. Acumulation of organic carbon in five brazilian lakes during the Holocene. Sedimentary Geology, 148:319-342.

Veloso H.P., Goes-Filho L., Leite P.F., Barros-Silva S., Ferreira H.C., Loureiro R.L., Terezo E.F.M. 1975. Folha NA.20 Boa Vista e Parte das Folhas NA.21 Tumucumaque, NB.20 Roraima e NB.21. Rio de Janeiro, Projeto Radambrasil: Vegetação, DNPM. p. 307-406.

Manuscrito AE 052/2006 Submetido em 30 de outubro de 2006 Aceito em 7 de agosto de 2007 